\title{
Energy and environment as the foundations for sustainable development
}

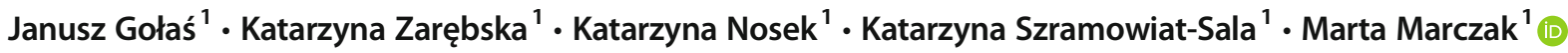

Received: 10 January 2019 / Accepted: 18 January 2019 / Published online: 7 March 2019

(C) Springer-Verlag GmbH Germany, part of Springer Nature 2019

Sustainable development is now one of the most frequently discussed multidimensional concept that orients plans and strategies for policymakers. Global pursuit towards sustainability forces solutions which should meet people's social, economic and environmental needs - for now, and for future generations. In between the social and economic aspects, the sector of energy and its production plays particular role. Not only in global scale, but for every single citizen the electrical power is indispensable - from food production, water supply, job creation, security etc. Energy sector simply influences sustainability of the entire economy. And, needless to say, the environment as well, since the energy industry contributes substantially to atmospheric contamination. Dwindling natural resources, raising consumption together with growing concern about environmental pollution stressed the importance of transition to cleaner technologies and developing alternative energies. Moreover, producing renewable energy, controlling urban air pollution and monitoring rural areas, reducing emission of toxic contaminants and identification of emerging environmental threats, i.e. protecting each component of the environment in any

Responsible editor: Philippe Garrigues

Janusz Gołaś

jgolas@agh.edu.pl

Katarzyna Zarę̧ska

zarebska@agh.edu.pl

Katarzyna Nosek

katarzyna.nosek@agh.edu.pl

Katarzyna Szramowiat-Sala

katarzyna.szramowiat@agh.edu.pl

Marta Marczak

mmarczak@agh.edu.pl

1 Faculty of Energy and Fuels, AGH University of Science and Technology, Al. Mickiewicza 30, 30-059 Krakow, Poland possible way, are consistent with the idea of sustainable world and simply make our planet "greener".

This special issue contains articles that discuss in a broad sense advancements on fossil fuel technologies preventing environmental pollution, describe the process of designing and deployment of energy-efficient, ecofriendly technologies and analyse the potential of renewable energy systems and waste utilisation. Selected publications have been presented at the 2nd International Conference on the Sustainable Energy and Environmental Development (SEED'17) in Krakow (Poland). The conference has been organized by the Institute of the Sustainable Energy (Krakow), Department of Sustainable Energy Development, Department of Coal Chemistry and Environmental Sciences and the Faculty of Energy and Fuels of AGH University of Science and Technology (Krakow) and held in the Krakow Technology Park on the November 14-17th, 2017. The SEED'17 conference has been awarded with honorary patronage by the Ministry of Science and Higher Education, Ministry of Energy, Ministry of the Environment, the Energy Regulatory Office, the Malopolska Provincial Office in Krakow, the City of Krakow, the National Representation of Doctoral Students (KRD) and the AGH University of Science and Technology. We have welcomed over two hundred participants of scientific and industrial background from all over the world: Malaysia, Singapore, Canada, the USA, Portugal, France, Belgium, Germany, Italy, Austria, the Czech Republic, Slovakia, Lithuania, Finland and Poland, representing over 50 institutions. The authors performed their excellent works on sustainable development in the fields of energy, fuels and environment, during 16 plenary and 3 poster sessions. Plenary sessions were opened by guest lecturers, Prof. Witold Brostow (University of North Texas), Prof. Laura Vanoli (University of Cassino and Southern Lazio), Prof. Tomas Salkus (Vilnius University) and Dr. Evert Bouman (Norwegian University of Science and Technology) who delivered superlative speeches on advancements in technology and the environment in the energy industry. We believe, that high quality of presented 
works, substantive discussions and welcoming social programme made the members satisfied and encouraged to participate in the next edition of the conference, which is planned to be held in 2019 .

The guest editors would like to thank all the authors for their contributions to this special issue as well as Professor Philippe Garrigues, the Editor-in-Chief of the Environmental Science and Pollution Research Journal, for kind support and helpful recommendations.

Acknowledgements Financial support from the statutory activity of the Department of Coal Chemistry and Environmental Sciences, AGH University of Science and Technology, Grant No. 11.11.210.374, is hereby acknowledged.

Publisher's note Springer Nature remains neutral with regard to jurisdictional claims in published maps and institutional affiliations.

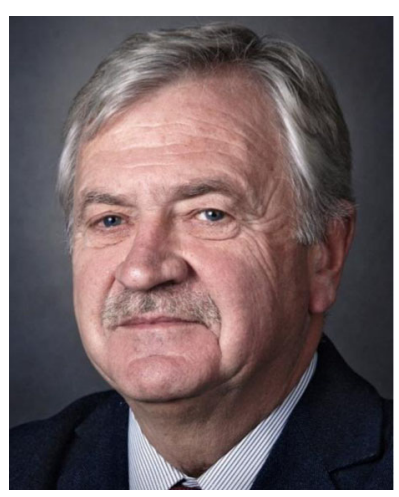

Janusz Gołaś is a full professor of chemistry at the Department of Coal Chemistry and Environmental Sciences, Faculty of Energy and Fuels, AGH University of Science and Technology (Poland). In 1982, he received his $\mathrm{PhD}$, in 1993 - DSc (both in chemistry, with honors), and in 2001, he became full professor at AGH. During the years 1984-1995, he worked for American universities and US government agencies: State University of New York (Buffalo), University of Illinois (Urbana), National Science Foundation (Washington D.C.), and collaborated with the Illinois Institute of Technology (Chicago) and San Diego State University (San Diego). Since 1995, Prof. J. Golas continues to be the head of the departments - at present, the Department of Coal Chemistry and Environmental Sciences, at the Faculty of Energy and Fuels, AGH. During the years 1995-2005, he was a Director of International School of Technology at AGH, established in collaboration with the Illinois Institute of Technology (USA). Since 2000, he has been a member of the Committee of Analytical Chemistry of the Polish Academy of Sciences. In 2016, Prof. J. Golas was appointed by the Polish Minister of Science and Higher Education as the member of the Committee of Science Policy. Prof. J. Golas authored and co-authored over 300 scientific papers, supervised $12 \mathrm{PhD}$ thesis and coordinated as a principal investigator 15 research and educational projects financed by national or international funds (e.g. The Kosciuszko Foundation, USA, Maria Curie Funds, USA, European Institute of Technology within the frames of KIC InnoEnergy). His research activities are focused on environmental analytical chemistry, especially in energy sector, analytics of mercury emitted during the combustion of solid fuels, analytics of emerging contaminants in environment, environmental protection and electroanalysis.

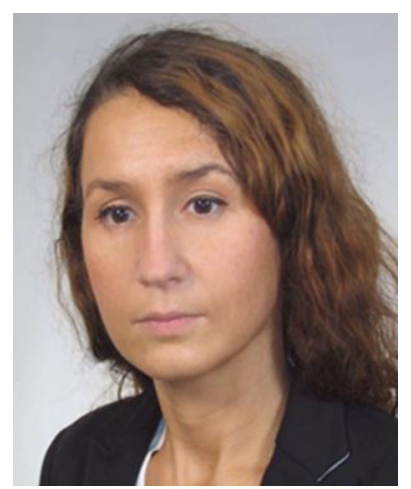

Katarzyna Zarębska is an associate professor at the Department of Coal Chemistry and Environmental Sciences, Faculty of Energy and Fuels, AGH University of Science and Technology (Poland). In 2003, she received $\mathrm{PhD}$ in chemical technology (with honors) at AGH-UST and in 2013-DSc in the field of engineering at Central Mining Institute in Katowice (Poland). Prof. K. Zarebska has published over 60 papers in peerreviewed journals, participated in 6 research projects. She has wide experience in the area of environmental monitoring and protection, atmospheric chemistry, mineralogy and crystallography. Recently, Prof. K. Zarebska works on the relations between the properties of bituminous coals and their sorption capacity during sorption/desorption of $\mathrm{CO}_{2}$; studies unconventional gas deposits, in the context of coal gasification and use in production of hydrogen as an universal energy carrier; and analyses particular groups of adsorbates in order to find the parameters of porous structure of coal adsorbents having different chemistry.

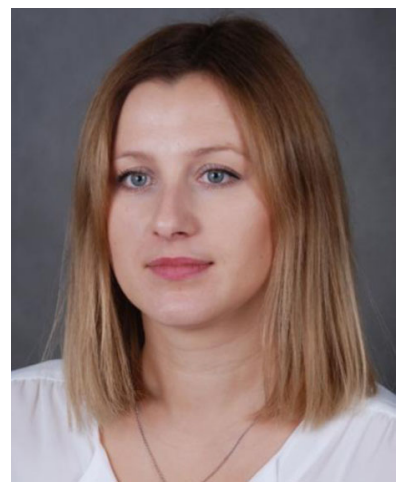

Katarzyna Nosek is a research associate at the Department of Coal Chemistry and Environmental Sciences, Faculty of Energy and Fuels, AGH University of Science and Technology (Poland). She graduated in 2008 in environmental engineering, and in 2014, she obtained her doctoral degree (with honors) in engineering in the field of chemical technology, AGH. As a $\mathrm{PhD}$ student, she was awarded with scholarships at academic, provincial and international levels (e.g. the Kosciuszko Foundation scholarship for $\mathrm{PhD}$ students with preeminent research achievements, 2009). In 2012-2013, she participated in educational project KIC InnoEnergy, funded by EIT European Institute of Innovation \& Technology, holding position of an Asssistant of Transition and Alumni Officer. Dr. K. Nosek is the author or co-author of 11 peerreviewed publications and has participated in 6 research projects financed by national or academic funds. Her research areas cover pharmaceutical metabolites and transformation products as emerging contaminants in the aquatic environment, the fate of pharmaceutical metabolites in the environment, developing and optimizing analytical methods for determination pharmaceutically derived compounds in water samples and evaluation of removal efficiency during water treatment processes. 


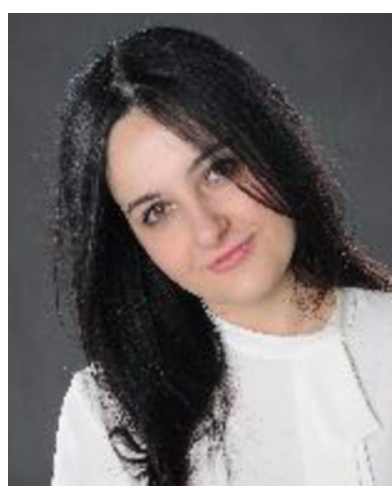

Katarzyna Szramowiat-Sala is an assistant professor in the Department of Coal Chemistry and Environmental Sciences at the Faculty of Energy and Fuels of AGH University of Science and Technology in Krakow. She graduated from the AGH-UST in 2012, and in 2017, she obtained a $\mathrm{PhD}$ degree (with honors) in the research field of chemical characterization of atmospheric aerosols and identification of sources of their occurrence in the atmosphere. She is an author and a co-author of 18 scientific articles. She actively participated in 15 international and in 11 national scientific conferences. She actively participated in research projects funded by the European Union, Polish Ministry and academic resources. She was/is a member of Organizing Committee of 4 international scientific conferences, including the series of SEED Conference (International Conferences on the Sustainable Energy and Environmental Development). She is the co-founder and member of Institute for Sustainable Energy. She coordinated and participated in several social projects aiming at the improvement of ecological awareness of students and other inhabitants of Krakow agglomeration.

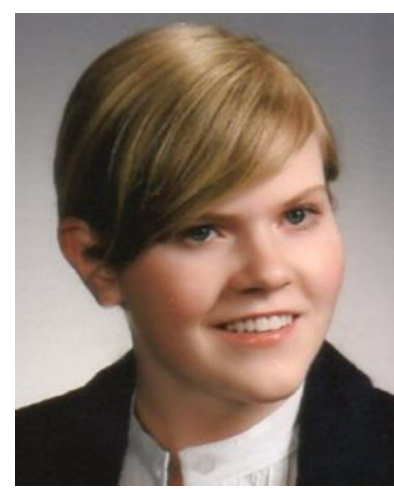

Marta Marczak is a PhD Student at the Department of Fuels Technology, Faculty of Energy and Fuels, AGH University of Science and Technology (Poland). She graduated in 2015 in the field of chemical technologies in the energy sector AGH. As a student, she was awarded with scholarships at academic and international levels (e.g. DAAD scholarship for foreign students, 2013) and she was served national and international apprenticeships (e.g. Vienna University of Technology, Institute of Chemical Technologies and Analytics, 2015). M. Marczak is the author or co-author of 8 peer-reviewed publications, participated in 6 research projects financed by international, national or academic funds. Her research areas cover mercury removal from flue gases during coal combustion. The purpose of the study is to understand mercury behaviour during subbituminous coal and lignite combustion for flue gas purification in terms of reduction of emissions through implementation of new, cost-efficient methods (co-benefits mercury removal, utilizing a cheap sorptive material) that minimize negative impact of mercury on the environment. 